\title{
0 trabalho na enfermagem e seu significado para as profissionais
}

\author{
Nursing work and its meaning to female professionals \\ El trabajo de enfermería y su significado para las profesionales
}

Thelma Spindola

Doutora em Enfermagem. Professora Adjunto da Faculdade de Enfermagem da Universidade do Estado do Rio de Janeiro (UERJ). Enfermeira do HUGG da Universidade Federal do Estado do Rio de Janeiro (UNI-RIO).

Rosângela da Silva Santos

Doutora em Enfermagem. Professora Titular do Departamento de Enfermagem Materno-Infantil da EEAN/UFRJ. spindola@centroin.com.br

\section{RESUMO}

Trata-se de um estudo qualitativo com emprego do método História de Vida tendo como objetivos descrever o cotidiano da mulher-mãe-trabalhadora de enfermagem e analisar a percepção desta profissional em relação ao seu cotidiano tomando como base sua história de vida. Foram entrevistadas 25 profissionais de enfermagem, que tivessem filhos, de um hospital geral público no município do Rio de Janeiro. A análise dos relatos evidenciou que as trabalhadoras visualizam o enfermeiro como um profissional polivalente que se envolve com toda a dinâmica da organização hospitalar por falta de delimitação das ações de enfermagem. A precariedade das condições da instituição pública no atendimento à população, traduzida pela insuficiência de recursos, interfere diretamente no fazer da enfermagem.

Descritores: Trabalho feminino; Enfermagem; Pesquisa qualitativa.

\section{ABSTRACT}

This is a qualitative study that used Life History method aiming to describe the woman-mother-nursing laborer's daily routine and to analyze the woman-mother-nursing laborer's perception of their daily routine, based on their life history. Twenty-five nursing professionals of a public general hospital in Rio de Janeiro, who had children, were interviewed. The report analysis revealed that these laborers see nurses as multivalent professionals, who are involved in the whole hospital organization dynamics, due to lack of delimitation of the nursing actions. The precariousness of the conditions in which the population of this public institution is assisted, manifested by resources insufficiency, directly interferes in the nursing activity.

Descriptors: Feminine labor; Nursing; Qualitative research.

\section{RESUMEN}

Se trata de un estudio cualitativo que utilizó el método de Historia de Vida para describir el cotidiano de la mujermadre-profesional de enfermería y analizar la percepción de la mujer-madre-profesional de enfermería con relación a su cotidiano, teniendo como base su historia de vida. Fueron entrevistadas 25 profesionales de enfermería, que tenían hijos, de un hospital general público del municipio de Rio de Janeiro. El análisis de los relatos evidenció que las trabajadoras visualizan el enfermero como un profesional polivalente que se compromete con toda la dinámica de la organización hospitalaria, debido a la falta de delimitación de las acciones de enfermería. La precariedad en las condiciones asistenciales a la población de la institución pública, traducida por la insuficiencia de recursos, interfiere directamente en la actividad de enfermería.

Descriptores: Trabajo femenino; Enfermería; Investigación cualitativa

Spinola T, Santos RS. O trabalho na enfermagem e seu significado para as profissionais. Rev Bras Enferm 2005 mar-abr; 58(2):156-60.

\section{INTRODUÇÃO}

O interesse pela temática - a mulher e o trabalho - emergiu no contexto familiar onde as mulheres não exerciam atividades remuneradas. Cresci sendo estimulada a ter um destino diferente, assumindo uma profissão. Ao realizar o Vestibular optei pela enfermagem, pela afinidade com a área e em decorrência de minha vivência como instrumentadora cirúrgica.

Ainserção da mulher no mercado de trabalho mudou o curso da história. Tem sido uma caminhada longa e árdua, com perdas e conquistas, às custas de dor e sofrimento ${ }^{(1)}$. Os patrões muitas vezes preferiam a mão-de-obra feminina por ser mais barata e melhor. Entretanto, as qualidades inerentes ao gênero são deturpadas em seu próprio detrimento e os elementos morais e delicados de sua natureza são utilizados contra ela, escravizando-a e fazendo-a sofrer, lembra a autora.

O trabalho feminino foi lenta e tardiamente regulamentado em decorrência da falta de organização das mulheres em sindicatos, da sua tradição de resignação e submissão e da falta de solidariedade 
e consciência coletiva diante das novas possibilidades que se apresentavam. Assim, as trabalhadoras contentavam-se com os baixos e distintos salários que recebiam, denotando que não sabiam defenderse de seus exploradores ${ }^{(1)}$. Quando as mulheres se integraram na vida sindical, é que puderam defender seus próprios interesses e deixar de pôr em perigo os da classe operária em seu conjunto. A despeito de todas essas dificuldades, a evolução do trabalho feminino prosseguiu(1).

Mas as condições de trabalho não são semelhantes para mulheres e homens. Existem distinções nas atividades realizadas, nos cargos ocupados e na remuneração que, em muitas situações, é inferior à do homem no desempenho da mesma função. Este problema decorre da diferença entre a natureza das ocupações e a magnitude das jornadas de trabalho, fatores que pressionam a mulher a tentar conciliar sua vocação profissional com a necessidade financeira visando a sobrevivência e/ou o desenvolvimento da família, levando-as a buscar e/ou aceitar ocupações que possam desenvolver em tempo parcial, 0 que resulta em menor rendimento salarial(2).

A inserção da mulher no mercado de trabalho provocou alterações significativas em seu cotidiano num processo que adquiriu dimensão estrutural no mundo contemporâneo. Um dos fatores que mais radicalmente contribuíram para a redefinição da posição social da mulher foi 0 advento de métodos anticoncepcionais, com conseqüências decisivas nas relações familiares, gradativamente modificadas em sua organização, inclusive em relação à divisão de tarefas domésticas e educação dos filhos ${ }^{(3)}$. Entretanto, no Brasil, a entrada feminina no mundo do trabalho, nas duas últimas décadas, não teve o mesmo impacto para todas as mulheres: 0 trabalho remunerado implicou uma mudança significativa no modo de vida das mulheres com qualificação profissional, que graças não só a expansão do mercado de trabalho mas também do sistema educacional brasileiro, tiveram condições de romper com 0 padrão de divisão sexual da geração de suas mães, que "não trabalhavam" (leia-se remuneradamente), alterando, assim, a organização de sua vida familiar ${ }^{(3)}$.

As mulheres trabalhadoras concentram-se em verdadeiros guetos ocupacionais, diferenciados por classes sociais e nível de escolaridade em especial no setor terciário da economia, e, dentro destes, no ramo do trabalho doméstico, cujas atividades têm pouco ou nenhum prestígio social. Apesar disto, têm estado presentes nas atividades de nível médio, especialmente naquelas de cunho administrativo e comercial, sendo que 0 ensino e a enfermagem, por suas características femininas, as carreiras preferidas daquelas que completam o nível superior ${ }^{(4)}$.

Acerca da relação escolaridade/inserção no mercado de trabalho, autoras $^{(4,5)}$ destacam que as mulheres instruídas são as que, proporcionalmente, mais integram o sistema produtivo, em função do tipo de atividade mais gratificante que realizam ou de uma remuneração que compense os gastos necessários para justificar sua ausência do lar.

Por outro lado, vale salientar que a participação da mulher no sistema produtivo é definida não só pelas condições oferecidas no mercado de trabalho, como também pelas potencialidades da mulher para inserirse neste espaço. Assumem importância, neste contexto, características individuais como condição marital, número de filhos, idade e escolaridade que, com outros atributos, determinam e/ou facilitam/dificultam a sua inserção no sistema produtivo(5).

Quanto à enfermagem como opção profissional decorre do fato de ser uma profissão de mulheres, do gênero feminino, que envolve representações sociais inerentes às "características" da mulher ideal numa sociedade ainda dominada pelos homens, tais como: submissão, abnegação, disciplina, pureza, humildade e domesticidade ${ }^{(6)}$. Assim sendo, foi só deslocar uma cultura pronta, que era da mulher, mãe e esposa no espaço privado cuidando da casa, dos filhos e do marido, para o espaço público: substitui-se, neutralizando, a casa pelo hospital, os filhos pelos sujeitos do cuidado, o povo e o marido pelo médico(6).
Neste sentido, o fato de a enfermagem ser exercida majoritariamente por mulheres torna-se relevante quando se analisam os determinantes e a organização dessa prática social, que a associam aos estereótipos que cercam a vivência feminina na sociedade ${ }^{(4)}$. 0 trabalho da enfermagem é característico sendo um meio rico em que rola a valorização do único, do particular, do específico, do subjetivo, do senso comum, das crenças, dos mitos, dos rituais, do místico, do conhecimento popular e do benefício social. A procura do significado e compreensão para os próprios hábitos de vida dos trabalhadores de enfermagem inseridos no dia a dia de uma dinâmica organizacional pode ser encontrada através das categorias compreensivas de análise sócioantropológica do quotidiano destes trabalhadores ${ }^{(7)}$.

Deste modo, as singularidades do trabalho da enfermagem são marcantes não somente por caracterizar-se como profissão essencialmente integrada por mulheres, como também, pela especificidade das ações que desenvolvem no dia-a-dia.

O trabalho de enfermagem é constituído por atividades relativas ao cuidado e administração do espaço assistencial, organizado sob a égide da divisão parcelar ou pormenorizada do trabalho. Desde sua organização, a profissão "é predominantemente subordinada e assalariada"(8). A profissão organiza-se dentro do sistema capitalista de produção e, apesar de deter certa autonomia em relação aos demais profissionais de saúde, encontra-se subordinada ao gerenciamento do ato assistencial realizado pelos médicos ${ }^{(8)}$.

Ao discutirem alguns problemas ocupacionais da enfermagem no Brasil, as autoras ${ }^{(9)}$ afirmam que em grande parte da nação brasileira, a Enfermagem ainda encontra-se cerceada, sem soberania, submissa ao seu empregador que, em geral, espera que ela cumpra apenas as ordens médicas, sem grandes questionamentos. Com a fala resignada que tudo acaba sobrando para a Enfermagem, seus profissionais suportam ordens agressivas, descasos de outros profissionais, opressão de seu empregador, entre outros problemas ${ }^{(9)}$.

A assistência de enfermagem nas instituições públicas, em geral, tem sido penalizada com a deficiência dos recursos humanos e materiais, o que interfere diretamente na qualidade da assistência prestada à população, gerando insatisfação nos profissionais que se sentem impotentes e frustrados com a situação. Este quadro foi analisado por autores $^{(10-12)}$ dentre outros, ao descreverem a realidade dos profissionais de enfermagem nos Hospitais Universitários, retratando o sofrimento dos trabalhadores com as condições cotidianas de trabalho.

Para clarificar o pensar das trabalhadoras de enfermagem acerca das ações que desenvolvem em seu cotidiano, optamos pela realização de um estudo tendo como objetivos: Descrever o cotidiano da mulhermãe-trabalhadora de enfermagem e analisar a percepção da mulhermãe-trabalhadora de enfermagem em relação ao seu cotidiano tomando como base sua história de vida.

\section{METODOLOGIA}

Trata-se de um estudo descritivo em abordagem qualitativa com emprego do método de história de vida o qual, trabalha com a estória ou o relato de vida, contada por quem a vivenciou ${ }^{(13)}$. Assim, o que interessa ao pesquisador "é o ponto de vista do sujeito. $O$ objetivo desse tipo de estudo é justamente apreender e compreender a vida conforme ela é relatada e interpretada pelo próprio ator"(14).

O método de história de vida é necessariamente histórico (a temporalidade contida no relato individual remete ao tempo histórico), dinâmico (apreende as estruturas de relações sociais e os processos de mudança) e dialético (teoria e prática são constantemente colocados em confronto durante a investigação) ${ }^{(15)}$.

O estudo foi realizado em um Hospital Público Federal do Município do Rio de Janeiro, onde foram entrevistadas 25 trabalhadoras, sendo 08 enfermeiras e 17 técnicas ou auxiliares de enfermagem lotadas no 
serviço diurno, em função da maior concentração de mulheres/mães no referido horário. Seguindo-se as recomendações da resolução 196/96 de pesquisas com seres humanos ${ }^{(16)}$ foi solicitada autorização à Superintendência de Enfermagem e Direção do Hospital. Ressalta-se que, na ocasião da coleta dos dados, a Comissão de Ética da Instituição estava em fase de transição e o Diretor do Hospital e a Superintendente de Enfermagem concederam a autorização solicitada que, posteriormente, foi ratificada pela Comissão de Ética.

Participaram do estudo trabalhadoras de enfermagem que tinham filhos. Não foram delimitadas as idades das mulheres e dos seus filhos, uma vez que não houve preocupação em formar grupos, e sim compreender melhor como elas vivenciavam seu cotidiano de mãe, mulher e trabalhadora. Nesse sentido a autora ressalta que "é através da análise das práticas diárias dos indivíduos que se pode chegar a uma compreensão da dinâmica da personalidade de uma pessoa, ou das características e atitudes de um grupo social"(14).

Às mulheres foi apresentada a questão: Fale-me de sua vida, de seu cotidiano como mulher, mãe e trabalhadora de enfermagem e, em conformidade com o método história de vida. Utilizamos o recurso de gravação em fita magnética, mediante prévia aquiescência das depoentes, visando a garantia do anonimato e a fidedignidade daquilo que havia sido dito durante as entrevistas. Foram realizadas 25 (vinte $e$ cinco) entrevistas, julgadas suficientes após a constatação de que os relatos tornavam-se repetitivos, significando terem atingido o ponto de saturação, ou seja, não acrescentavam fatos novos ao que fora dito anteriormente ${ }^{(13)}$

A análise dos relatos permitiu a categorização das entrevistas traduzindo o pensamento das mulheres sem omitir a sua opinião. Assim, foram organizados em três grandes categorias com sub-categorias dentre essas "O trabalho e seu significado" onde foi explicitado o pensar das trabalhadoras acerca do trabalho remunerado e o significado deste em suas histórias de vida. Uma das sub-categorias deste grupo é a visão das mulheres em relação ao tipo de atividade que realizam como profissionais de enfermagem denominada $O$ trabalho na enfermagem $e$ suas condições. Para garantir 0 anonimato das depoentes foram utilizados pseudônimos.

\section{ANÁLISE DOS RELATOS}

O trabalho remunerado assume papel importante nos relatos das mulheres entrevistadas, sendo percebido como uma forma de a mulher adquirir sua independência, conquistar seu espaço na sociedade e ver seu trabalho reconhecido. $O$ trabalho na enfermagem e suas condições foram ressaltados nos relatos a seguir, evidenciando o que é ser uma trabalhadora desta área e como ocorre sua prática profissional nas instituições de saúde pública do município do Rio de Janeiro:

[...] É aquele que resolve tudo, o polivalente. [...] Trabalha [...] antes, [....] durante e [...] depois [...] e [...] se cansa mais. [...] Porque a gente anda mais, [...] carrega mais peso, [...] tem que se preocupar com o que aconteceu ontem, o [...] hoje, e o [...] amanhã. [...] Nós lidamos diretamente com todas as pessoas do hospital [...] o elo entre todos os outros funcionários [...] (Maria, 31 anos, Enfermeira)

[...] eu acho que temos uma profissão difícil que exige muito da gente física e emocionalmente [...] já estou me sentindo cansada, exausta porque vejo que a cada dia as dificuldades se tornam maiores em termos de pessoal, de material [...]. A gente se sente impotente [...] quer fazer o melhor e acha que[...] não tem condições [...] porque isso envolve muita coisa [...] me deixa frustrada, [...] angustiada. Tem dias que eu chego em casa muito triste, com vontade de [...] abandonar tudo; mas, são 18 anos na profissão, e eu acho que vale a pena esperar mais um pouquinho para [...] me aposentar. (Alcina, 39 anos, Aux. Enfermagem)

Nestes relatos notamos que o enfermeiro é visualizado como um profissional que se envolve em muitas ações na organização hospitalar, e fica sobrecarregado com o acúmulo de funções e preocupado com a organização e planejamento das ações de enfermagem. A precariedade das condições do hospital público, também foi retratada, evidenciando uma interferência negativa no fazer da enfermagem, ao gerar sensações de impotência, frustração e angústia entre as trabalhadoras. Aspectos como a deficiência relacionada aos recursos humanos e materiais, a própria estrutura física da instituição, que não dispõe de acomodações apropriadas para os profissionais de enfermagem realizarem suas refeições e/ou descansarem, contribui para a insatisfação das servidoras, como afirma Alcina.

O fazer e as ações de enfermagem foram descritos por diversos autores. Mais recentemente, discutindo o processo de trabalho nas organizações de saúde do Brasil, verificou-se que o trabalho assistencial institucionalizado resultava do trabalho em equipe "no qual o médico é o elemento central que detém o controle do processo assistencial e delega atividades a outros profissionais de saúde"(8). Sendo assim, a enfermagem é a responsável pelo cuidado direto aos pacientes, assistindo-os durante as 24 horas do dia, num trabalho realizado por uma equipe integrada por enfermeiro, técnico, auxiliar de enfermagem com formação diferenciada e funções distintas.

As ações da enfermagem estão amparadas pela Lei do Exercício Profissional - Lei $n^{0} 7498 / 86^{(17)}$, que define as competências de cada profissional. 0 enfermeiro gerencia o trabalho dos demais membros da equipe; presta cuidados especiais, definidos pela legislação como de sua exclusiva competência; e domina os conhecimentos relativos ao exercício do trabalho assistencial da enfermagem, avaliando as necessidades de cada paciente. Os demais membros da equipe executam as ações prescritas pelo médico e pelo enfermeiro, sempre sob sua supervisão.

Discutindo as condições psicológicas do trabalho e suas conseqüências sobre a saúde do trabalhador, os autores ${ }^{(18)}$ afirmam que a organização do trabalho é um fator potencialmente desestabilizador da saúde mental dos trabalhadores. Assim correlacionam o fazer dos trabalhadores com seus sentimentos, acreditando que as pessoas, em muitas situações, somatizam e acabam ficando doentes em decorrência de situações insatisfatórias no próprio ambiente de trabalho. No caso da enfermagem a insatisfação e a frustração das trabalhadoras ficou clara nos relatos, sendo citados como aspectos negativos 0 ambiente físico onde as ações se desenvolvem, a deficiência de recursos humanos e materiais, a própria organização do trabalho (fragmentado pela divisão de tarefas executadas em turnos) todos eles alienantes e, portanto, prejudiciais à saúde das mesmas.

A adaptação/identificação com o local de trabalho e a necessidade de reciclagem dos profissionais são aspectos, também, presentes nos relatos das trabalhadoras, como podemos observar:

[...] porque eu acho muito ruim você fazer o que não gosta, (...) eu aprendi a gostar porque eu sou sanitarista eu não sou intensivista, (...) Quando eu vim para cá como eu não tive condições de trabalhar nisso, então eu comecei a investir em outra coisa, mas para mim tudo era um desafio, (...) e acho que o aprendizado assim nunca se perde nada com ele pelo contrário, (...) agora estou até pensando em fazer um curso de especialização em CTI [...] (Selma, 35 anos, Enfermeira)

[...] porque nem sempre a gente trabalha dentro daquilo que gostaria de trabalhar. (...) eu passei por vários setores (...) mas não era o setor que eu me identificava mais, (...) procurei desenvolver da melhor maneira possível a atividade. (...) Falta de uma estrutura que dê para você trabalhar melhor (...) para você fazer até um curso para se atualizar, (...) isso também a gente não consegue fazer, se você sai para um curso todo mundo fala (...) que já está sem pessoal. [....] (Maria, 31 anos, Enfermeira) 
Os relatos deixam transparecer duas situações bastante comuns no trabalho da enfermagem: a primeira, relacionada com a adaptação/ identificação com setor de trabalho; a segunda, diz respeito à reciclagem de conhecimentos. Em geral, infelizmente, são poucas as Instituições de saúde que se preocupam em fazer um levantamento das aptidões/ áreas de interesse de seus servidores, antes de alocá-los em determinado setor. Com isso os ajustes acabam ocorrendo naturalmente, pois a pessoa precisa se adaptar ao serviço. Se não ocorrem, causam sofrimento ao trabalhador designado para aquele setor, como o relato de Selma explicita.

Em grandes organizações são comprovados os resultados em que o trabalhador, satisfeito com o local e tipo de trabalho que executa, tem um desempenho melhor. Todavia, na enfermagem nem sempre este fator é considerado gerando insatisfação entre os profissionais. Isto porque, poucos são os gerentes de enfermagem que estão atentos para a tríade identificação/satisfação/melhor aproveitamento do trabalho. Neste sentido o autor ${ }^{(19)}$ lembra que "a relação do homem com a organização do trabalho é a origem da carga psíquica do trabalho". Ou seja, quanto mais harmoniosa for a relação do homem com o seu trabalho, melhor será a sua saúde psíquica. Assim, quanto maior for 0 equilíbrio entre a relação de trabalho e o trabalhador, mais capacitado estará para utilizar plenamente suas potencialidades no desenvolvimento de suas aptidões, e em condições de sentir prazer na realização destas tarefas.

Em relação à reciclagem de conhecimentos, foram explicitadas pelas trabalhadoras a importância e a necessidade de fazê-la; todavia, deixaram claro que esta não é uma constante na referida Instituição, em função do déficit de pessoal e da falta de uma política de capacitação profissional. Assim, entregues à própria sorte, a iniciativa de procurar aperfeiçoar-se fica a critério de cada servidora, que não recebe estímulos ou qualquer tipo de apoio financeiro/institucional para realizar estas ações, como reforça Selma. Deixam também transparecer que, no caso de alguma indicação para o profissional capacitar-se, o grau de insatisfação entre os demais colegas será grande, sob a alegação de déficit de pessoal, o que na verdade evidencia a falta de uma política de investimentos nos trabalhadores e a própria fragilidade da organização, que acaba não avaliando adequadamente o retorno do benefício, para a Instituição através destas ações.

A responsabilidade do profissional de enfermagem, seu compromisso e a falta de valorização dos trabalhadores pelos demais membros da equipe de saúde foram verbalizados pelas entrevistadas, conforme os relatos a seguir:

[...] Outros profissionais não te valorizam, (...) os auxiliares e técnicos. (...) A área acadêmica, o profissional de enfermagem (refere-se ao docente) é mais valorizado, tem oportunidade de se reciclar, (...) de cursos. O profissional de assistência, como eu, quase não tem. (...) eu não gosto de não ser valorizada. Eu acho que (...) a enfermagem não é valorizada. É sempre o último que sabe das coisas (...) que resolve.(...) Por não ser valorizada, não crescer, não vê crescimento.(...) É sempre a mesma coisa.[...] (Eduarda, 42 anos, Enfermeira)

[...] Aquela forma de ver o enfermeiro como um profissional de nível superior, que fez também uma faculdade, que tem (...) consciência da administração hospitalar e faz tudo com embasamento técnicocientífico (...) tudo isso se perde entre os outros profissionais.(...) porque você é muito cobrada. (...) Então se não tem alguma medicação na Farmácia, (...) você é o culpado de não ter vindo.(...)

Se o exame não foi feito é porque você não orientou bem o cliente [...] (Maria, 31 anos, Enfermeira)

As profissionais de enfermagem percebem em seu cotidiano a grande responsabilidade que têm, envolvidas que estão com a preservação da vida das pessoas a quem prestam cuidados. Na prestação da assistência as atividades da equipe de enfermagem são diferenciadas conforme a categoria funcional, como preconiza a Lei $n^{0} 7498 / 86$ que normatiza 0 exercício profissional de enfermagem ${ }^{(17)}$. Os enfermeiros realizam a gerência do cuidado, ou seja, o planejamento das ações de enfermagem, a provisão e previsão de material, além de prestarem cuidados aos pacientes mais graves, que exijam conhecimentos científicos e tomada de decisões. 0 técnico e 0 auxiliar de enfermagem realizam atividades de natureza repetitiva, sob supervisão do enfermeiro. Na verdade, muitas vezes, esta é a razão dos conflitos existentes no relacionamento entre estes profissionais, ou seja o fracionamento das ações que desenvolvem e a própria divisão do trabalho. Como existem trabalhadores de níveis distintos de escolaridade, àquele que determina/orienta a ação e o que executa, a harmonia entre estas pessoas fica muito prejudicada, ocorrendo mais em função da empatia e integração que se estabelece entre eles.

Por outro lado, a desvalorização da profissão, mencionada pelas entrevistadas, está associada à distinção entre o Saber e o Fazer. Assim é que a enfermagem, como um todo, é percebida pelos demais profissionais da área de saúde como aquela que faz, que está diretamente em contato com os pacientes, a cuidadora. 0 fato de a profissão ser realizada por pessoas de níveis diferenciados contribui para que os demais profissionais da saúde nem sempre enxerguem 0 enfermeiro como um profissional de nível superior, com embasamento científico e assim, acabam por tratá-lo sem a devida consideração, como refere Maria em seu relato. Todavia, existe outro fator a ser considerado, e que está relacionado ao gênero, ou seja, o de que a enfermagem é uma profissão essencialmente feminina e, neste sentido, a desvalorização decorreria disso? Trabalhando com a questão do gênero na enfermagem, a autora ${ }^{(20)}$ discutiu este aspecto da desvalorização da profissão afirmando que "o fato da Enfermagem ser uma profissão majoritariamente feminina se constitui em uma das possibilidades para se chegar à explicação e compreensão do seu estado atual de crise de identidade, de prestígio social, de força política dentre outras, sendo portanto, impossível descolar as questões que envolvem essa profissão da própria história das mulheres".

Outro aspecto que merece ser pontuado está relacionado à falta de delimitação das ações de enfermagem, referida por Maria, levando a que sejam consideradas culpadas pelas falhas administrativas do hospital. Assim, toda a infra-estrutura relativa à prestação de assistência oferecida pelas instituições de saúde acaba se refletindo no processo de cuidar. Na falta dos recursos necessários para a realização das ações de saúde, alguém será responsabilizado e, freqüentemente, conforme a trabalhadora afirma, a culpa recai sobre a enfermagem.

Neste sentido, ratifica-se o pensamento da autora(8), que afirma a enfermagem é "cobrada" pelos médicos, pelos pacientes, por familiares e pela administração. No entanto, o seu poder decisório é pequeno, depende de outros setores e as regras de funcionamento da instituição delimitam as suas potencialidades de ação.

A relação do homem com o trabalho é significativa para a sua saúde psíquica conforme ressalta 0 autor ${ }^{(19)}, 0$ organismo do trabalhador não é um "motor humano", na medida em que é permanentemente objeto de excitações, não somente exógenas, mas também endógenas. 0 trabalhador não chega a seu local de trabalho como uma máquina nova. Ele possui uma história pessoal que se concretiza por uma certa qualidade de suas aspirações, de seus desejos, de suas motivações, de suas necessidades psicológicas.

Assim sendo, é necessário que o trabalhador sinta-se estimulado, que se identifique com o tipo de tarefa que está realizando, para que se estabeleça uma relação de prazer com o trabalho. Do contrário, 0 trabalho tornar-se-á uma fonte de tensão e desprazer.

\section{CONSIDERAÇÕES FINAIS}

A vivência de uma das pesquisadoras como trabalhadora de enfermagem no contexto de uma instituição pública de assistência à saúde e as dificuldades do dia-a-dia, inerentes ao desempenho 
profissional, foram o ponto de partida para a realização deste estudo.

A partir dos relatos das mulheres, foi possível construir o cotidiano $\mathrm{e}$ as vivências de cada trabalhadora, retratando-se a frustração e a impotência das mesmas diante da percepção acerca da assistência prestada num hospital público do município do Rio de Janeiro, onde atuam profissionalmente, decorrente da insuficiência de recursos materiais e humanos para 0 atendimento da clientela, da falta de reconhecimento da profissão pelos demais membros da área de saúde e pela própria sociedade.

Segundo as depoentes, o profissional de enfermagem é reconhecidamente polivalente e tende a envolver-se com a dinâmica da organização hospitalar, em geral, por falta de delimitação do seu campo de atuação. Este fato, associado a fatores como remuneração insuficiente, desvalorização do seu trabalho, cobrança excessiva por eventuais falhas no atendimento e falta de incentivo para capacitação, pode levá-lo a sentir angústia e sofrimento no exercício de suas funções

O perfil da enfermeira como pessoa devotada, abnegada, observadora, fiel e de sentimentos delicados, conforme definido na segunda metade do século XIX por Florence Nightingale ${ }^{(21)}$, persiste entre as profissionais ainda hoje, embora reconheçam as limitações do sistema de saúde vigente e a complexidade do assistir. E assim, esforçam-se no desempenho de suas funções para prestar um atendimento à clientela com base em princípios de dignidade e respeito à pessoa humana. Suas atividades fazem com que convivam diariamente com a morte e o morrer, com o sofrimento alheio, as carências da população e a dificuldade no processo de assistir, situações que as levam a ter suas vidas invadidas, de certa forma, pela história e problemática daqueles de quem cuidam, resultando num cotidiano repleto de emoções.

A situação atual da mulher brasileira difere bastante de outrora. Hoje ela necessita trabalhar para ajudar a compor a renda familiar. Seus ganhos, muitas vezes, não permitem que tenha apenas um emprego, como é o caso da maioria das trabalhadoras de enfermagem. Em geral, residem longe dos empregos, fazendo com que aumente o tempo em que permanecem ausentes de casa. Têm dupla ou tripla jornada, provocando esgotamento físico e mental, não restando tempo suficiente para dedicar aos seus interesses pessoais e assim, viver com tranqüilidade.

As profissionais de enfermagem do estudo têm estes comprometimentos em suas vidas. Trabalhar na área de enfermagem, com especificidade ímpar, associado às demais tarefas cotidianas como mulheres e mães, faz com que se sintam consumidas. Correlacionando a história de vida de cada uma às condições de trabalho que vivenciam no seu dia-a-dia nos deparamos com a questão da saúde mental das mesmas, lembrando que, em muitas situações, a mulher está assumindo sozinha o sustento da família e a educação dos filhos. Dentre as entrevistadas 09 mulheres não tinham companheiro e, portanto, são totalmente responsáveis por suas famílias.

Sendo o trabalho vital para o ser humano e interferindo diretamente em sua capacidade física e mental, como mencionado ao longo deste estudo, torna-se relevante a observação pelos gerentes das instituições de saúde dos fatores alienantes e nocivos à saúde dos trabalhadores, especialmente às mulheres profissionais de enfermagem, que necessitam manter-se íntegras física e mentalmente para o pleno exercício de suas atividades como trabalhadoras, mulheres e mães.

\section{REFERÊNCIAS}

1. Beavoir S. O segundo sexo. $5^{\mathrm{a}}$ ed. Rio de Janeiro (RJ): Nova Fronteira; 1980

2. Medici AC. Mulher brasileira: muito prazer. In: Labra ME, organizadora. Mulher, Saúde e Sociedade no Brasil. Petrópolis (RJ): Vozes/Abrasco; 1989. p.71-118.

3. Sarti CA. Os filhos dos trabalhadores: quem cuida das crianças? In: BRETAS ACP. Trabalho, saúde e gênero: na era da globalização. Goiânia (GO): AB; 1997. p.51-60.

4. Fonseca RMGS. Atenção: Mulheres Trabalhando! (na vida, na saúde, na enfermagem). In: Fonseca RMGS, organizadora. Mulher $e$ cidadania na nova ordem social. São Paulo (SP): NEMGE/USP; 1996. p. 97-110.

5. Bruschini C. Mulher e Trabalho: a brasileira conquista novos espaços. Mercado Global 1992; 87:52-8.

6. Sobral VRS. A purgação do desejo: Memórias de Enfermeiras. [Tese]. Rio de Janeiro (RJ): Escola de Enfermagem, Universidade Federal do Rio de Janeiro; 1994

7. Erdmann AL. O quotidiano nas organizações de enfermagem hospitalar- fundamentos para estudos. In: Rezende ALM, Ramos FRS, Patrício ZM, organizadores. 0 fio das moiras - 0 afrontamento do destino no quotidiano da saúde. Florianópolis (SC): UFSC; 1995. p. 121-36.

8. Pires D. Reestruturação produtiva e trabalho em saúde no Brasil. São Paulo (SP): CUT/ANNABLUME; 1998.

9. Robazzi MLCC, Marziale MHP. Alguns problemas ocupacionais decorrentes do trabalho de enfermagem no Brasil. Rev Bras Enferm 1999 jul-set; 52(3):331-8.

10. Lunardi Filho WD. Prazer e sofrimento no trabalho: contribuições à organização do processo de trabalho da enfermagem [dissertação]. Rio Grande (RS): Faculdade de Ciências Econômicas da Universidade do Rio Grande do Sul; 1995.

11. Spindola T, Lopes GT, Mertins ERC. A prática profissional na avaliação dos enfermeiros no contexto dos hospitais universitários. In: Anais do $50^{\circ}$ Congresso Brasileiro de Enfermagem; 1998 set 205; Salvador(BA), Brasil. Salvador (BA): ABEn; 1998. p. 189.

12. Spindola T, Martins ERC, Lopes GT. A prática de enfermagem nos Hospitais Universitários - percepção dos enfermeiros. Rev Enferm Esc Anna Nery 2001 ago; 5(2):181-90.

13. Bertoux D. L'approche biographique: sa valité méthodologique, ses potentialités. Cahiers Internationaux de Sociologie 1980; 59:197-225.

14. Glat R. Somos iguais a vocês: depoimentos de mulheres com deficiência mental. Rio de Janeiro (RJ): Agir; 1989.

15. Brioschi LR, Trigo MHB. Relatos de vida em ciências sociais: considerações metodológicas. Ciência e Cultura 1987 jul; 39(7):631-7.

16. Ministério da Saúde (BR). Conselho Nacional de Saúde. Diretrizes e normas regulamentadoras de pesquisas envolvendo seres humanos: Resolução nº 196/96. Brasília (DF): MS/FIOCRUZ; 1996.

17. Decreto-lei n $04.406 / 87$ de 08 de junho de 1987. Regulamenta a Lei 7498/86 sobre o Exercício da Enfermagem e dá outras providências. Diário Oficial - República Federativa do Brasil, Brasília (DF), 1987 jun; fls 8853-5.

18. Dejours $C$, Abdoucheli E, Jayet C. Psicodinâmica do trabalho: contribuições da Escola Dejouriana à análise da relação prazer, sofrimento e trabalho. São Paulo (SP): Atlas; 1994.

19. Dejours C. A carga psíquica do trabalho. In: Dejours C, Abdouchelil E, Jayet C. Psicodinâmica do trabalho: contribuições da Escola Dejouriana à análise da relação prazer, sofrimento e trabalho. São Paulo (SP): Atlas; 1994. p.21-32.

20. Nascimento ER. Gênero e Enfermagem. Salvador (BA): Positiva;1996.

21. Nlightingale F. Notas sobre Enfermagem. São Paulo (SP): Cortez; 1989. 